\title{
Transforming Growth Factor $\alpha$ (TGF $\alpha$ ) Expression in Degenerating Motoneurons of the Murine Mutant Wobbler: A Neuronal Signal for Astrogliosis?
}

\author{
Marie-Pierre Junier, ${ }^{1}$ Muriel Coulpier, ${ }^{2}$ Nadine Le Forestier, ${ }^{1}$ Josette Cadusseau, ${ }^{1}$ Fumio Suzuki, ${ }^{1}$ Marc \\ Peschanski, ${ }^{1}$ and Patrick A. Dreyfus ${ }^{2}$
}

'CJF INSERM 91-02, Fac Médecine, 94010 Créteil, France, and 2INSERM U153, 75005 Paris, France

\begin{abstract}
The enhanced expression of the trophic factor transforming growth factor $\alpha(\mathrm{TGF} \alpha)$ in reactive astrocytes following CNS injury suggests that TGF $\alpha$ has a role in the development of astrogliosis. We explored this hypothesis in the murine mutant wobbler, which presents a progressive motoneuronal degeneration associated with an astrogliosis. Evolution of astrogliosis, and expression of TGF $\alpha$ precursor (pro-TGF $\alpha$ ) and of its receptor were examined over the course of the disease, using genetically diagnosed animals and immunocytochemical techniques. We report here that degenerating motoneurons of the cervical spinal cord and a subset of astrocytes express pro-TGF $\alpha$, prior to the onset of astrogliosis, when the first clinical manifestations of the disease are observed at 4 weeks of age. TGF $\alpha$ expression appeared strongly correlated with motoneuronal degeneration. All pro-TGF $\alpha$-immunoreactive neurons exhibited a degenerative morphology, and the number of pro-TGF $\alpha$-immunoreactive neurons increased with the progression of the disease. At the glial level, we observed that astrogliosis was a transitory phenomenon in the wobbler mice, developing in coordination with the motoneuronal expression of pro-TGF $\alpha$. Astrogliosis became evident in 6-week-old wobbler mice, when the number of pro-TGF $\alpha$-immunoreactive motoneurons was maximal, and regressed in older mutant mice in correlation with the disappearance of pro-TGF $\alpha$-immunoreactive motoneurons. Furthermore, TGF $\alpha /$ EGF receptor immunoreactivity was exclusively localized in a subset of reactive astrocytes, its expression following closely the course of the astrogliosis. These data show that TGF $\alpha$ synthesis by the affected motoneurons is an early event in the course of the wobbler disease, and suggest a role for TGF $\alpha$ as a neuronal inducer of astrocytic reactivity.
\end{abstract}

[Key words: transforming growth factor $\alpha$, astrocyte, neurodegenerative disease, wobbler, motoneuron, spinal cord]

Upregulation of TGF $\alpha$, a structural and functional homolog of epidermal growth factor (EGF), endowed with mitogenic and

Received July 29, 1993; revised Nov. 24, 1993; accepted Dec. 31, 1993

This research was supported by "Association Française Contre les Myopathies" grants (M.P., P.A.D.) and fellowship (M.-P.J.). We thank Catherine Dumas for excellent animal care. We are grateful to Dr. Larry E. Gentry (Medical College of Ohio, Toledo, $\mathrm{OH}$ ) for his generous gift of the antibody 1296 and to Bristol-Myers Squibb Company for authorizing us to use the rat TGF $\alpha$ cDNA. We are indebted to Dr. John Harris for reviewing the manuscript, and to Dr. C. Henderson for helpful discussion.

Correspondence should be addressed to Marie-Pierre Junier, CJF INSERM 91 02, Fac Médecine, 8 rue du Général Sarrail, 94010 Créteil, France.

Copyright (C) 1994 Society for Neuroscience $0270-6474 / 94 / 144206-11 \$ 05.00 / 0$ neurotrophic activities (Derynck, 1988; Chalazonitis et al., 1992), has becn implicated in the CNS response to injury (Junier et al., 1991). Synthesized by a subset of neurons and astrocytes throughout the normal adult CNS (Wilcox and Derynck, 1988; Kudlow et al., 1989; Fallon et al., 1990; Seroogy et al., 1993), its overexpression by reactive astrocytes and that of its receptor, the TGF $\alpha$ /EGF receptor common to both EGF and TGF $\alpha$ (Derynck, 1988), have been described following mechanical and chemical injury of nervous tissues (Nieto-Sampedro et al., 1988; Junier and Peschanski, 1992; Junier et al., 1993). Together with the reported stimulatory effect of EGF on astrocytic proliferation and differentiation in vitro (Leutz and Schachner, 1981; Simpson et al., 1982; Honneger and Guentert-Lauber, 1983; Wang et al., 1989), these results suggest a role for TGF $\alpha$ in the control of astrocytic reactivity.

Studies of models of acute traumas, which trigger a rapid neuronal destruction, have led to the belief that astrogliosis is a consequence of neuronal death, and functions as a structural replacement of the dying neurons (Reier, 1986). Alternatively, reactive astrocytes may also be actively involved in degenerative events since they are associated with degenerating neurons (Reier, 1986). Reactive astrocytes are capable of altering neuronal metabolism, and hence affecting the fate of the wounded tissue beyond the maintainance of the tissue. Indeed, reactive astrocytes are characterized not only by an increased immunoreactivity for GFAP and an increase in the length of their processes, but also by elevated enzymatic activities and synthesis capabilities of various polypeptides, including several growth factors (Eddleston and Mucke, 1993).

In order to study the relationships between reactive glia and neurons undergoing degeneration, we took advantage of an animal syndrome of progressive neurodegeneration, the wobbler mouse, to unravel the participation of TGF $\alpha$ in the "cross talk" between reactive astrocytes and affected neurons.

The wobbler mouse possesses an inherited autosomal recessive mutation that results in the progressive degeneration of large motoneurons, making the wobbler mouse the closest animal model of infantile spinal muscular atrophy (Duchen and Strich, 1968). In the aged wobbler mice, the ventral horn of the cervical spinal cord retains only $50 \%$ of the normal number of motoneurons (Baulac et al., 1983). In addition to the degeneration of motoneurons, reactive astrogliosis has been described as the other prominent feature of the wohbler mutation (Laage et al., 1988).

We report here that induction of TGF $\alpha$ synthesis in the affected motoneurons is an early event in the course of the wobbler disease, which precedes the onset of a transitory astrogliosis and 
the enhanced expression of TGF $\alpha$ and TGF $\alpha / \mathrm{CGF}$ receptor by reactive astrocytes. These findings are consistent with a role for TGF $\alpha$ in the induction of astrogliosis by neurons undergoing progressive degeneration.

\section{Materials and Methods}

Animals. The wobbler mulation is first expressed 3-4 weeks after birth. To allow prediction of the mutation prior to the onset of the disease, we introduced a polymorphic genetic marker, the microsatellite of the glutamine synthetase gene $(\mathrm{G}, \mathrm{g})$, close to the $w r$ gene. The $\mathrm{C} 57 \mathrm{Bl} / 6 \mathrm{~J}$ mice $(+/ w r, g / g)$ were crossed with NZB mice $(+/+, G / G)$ as shown in Figure 1. The wobbler mice of the $\mathrm{N} 2$ generation carried the allele " $g$ " and has been named "new" for "NZB elicited wobbler." The heterozygotes carrying both alleles $(\mathrm{g} / \mathrm{G})$, and the homozygotes $(\mathrm{G} / \mathrm{G})$ were of the wild phenotype. The DNA was extracted from the tail of 4-d-old mice, and the alleles were analyzed through PCR amplification. The primers were chosen in order to amplify a microsatellite DNA located in the 5 ' noncoding region of the glutamine synthetase gene. This microsatellite contains a variable number of GT repeats that determines each allele "g" and "G." Forward and reward primer sequences were 5'-AGCTTTGGAGACAACAATTAGATC-3', for the forward primer, and 5'-GGATGGGGAAATGGTGGTACA-3', for the reward primer (Des Portes et al., 1993).

Immunohistochemistry. Animals received an overdose of sodium pentobarbitone and were perfused transcardially with warm heparinized saline followed by a phosphate-buffered solution $(0.1 \mathrm{M}, \mathrm{pH} 7.4)$ containing $4 \%$ paraformaldehyde and $4 \%$ sucrose. The spinal cords were immediately removed, postfixed for $4 \mathrm{hr}$ at $4^{\circ} \mathrm{C}$ in the same fixative, and placed in a phosphate-buffered solution containing $30 \%$ sucrose. Mutant mice $(w r / w r)$ and their normal littermates $(+/ l)$ were killed by pairs. They will be henceafter designed as wobbler and controls, respectively.

All experiments were performed on the cervical spinal cord, known to be the major site of motoneuron degeneration in the wobbler (Duchen and Strich, 1968; Andrews, 1975). The following ages were examined: 2,4 , and 6 weeks, 3 and 5 months. Two or three wobbler mice and agematched controls were examined at each time point. Sections obtained from wobbler and control mice littermates of a given age were processed simultaneously.

Cryostat sections ( $32 \mu \mathrm{m}$ thickness) were cut in the frontal plane. Immunohistochemistry was performed on free-floating sections in Tris, $0.05 \mathrm{M} ; \mathrm{NaCl}, 154 \mathrm{~mm}$; BSA, $0.02 \%$; Triton, $0.3 \% ; \mathrm{pH} 7.5$. After soaking in a solution of $1 \%$ hydrogen peroxide for $15 \mathrm{~min}$ to eliminate endogenous peroxidase activity, and several rinses, the sections were incubated overnight at $4^{\circ} \mathrm{C}$ in the appropriate dilution of the primary antibody, and immunocytochemical detection was achieved using the avidin-biotin complex immunoperoxidase technique. TGF $\alpha$-immunoreactive cells were identified with polyclonal antibody $1296(1: 10.000)$ that recognizes a peptide sequence (amino acids 137-151) contained within the cytoplasmic domain of the TGF $\alpha$ precursor (Gentry et al., 1987). Control experiments included substitution of the primary antiserum with nonimmune serum and preadsorbtion of the primary antiserum with its antigene $(10 \mu \mathrm{g} / \mu \mathrm{l}$ antiserum). The use of an antiserum that recognizes the intracellular portion of the TGF $\alpha$ precursor ensured the identification of the cells that synthesize TGF $\alpha$, as opposed to cells capable of binding the growth factor. Adjacent sections were stained either for glial fibrillary acidic protein (GFAP), a specific marker of astrocytes (Dakopatt, DK; 1:5000), or for TGF $\alpha / E G F$ receptor using the polyclonal antibody Ab4 (Oncogene, USA; 1:500). This antiserum recognizes a peptide scquence (amino acids 1005-1016) localized within the intracellular carboxy-terminal tail of the TGF $\alpha / E G F$ receptor. Alternate sections were counterstained with cresyl violet before dehydration and final mounting. Control experiments included substitution of the primary antiserum with preimmune serum and omission of the secondary antibody. Double immunocytochemical detection was performed using nickel chloride as the first chromogen, visualized as a blue precipitate, and diaminobenzidine as the second, visualized as a brown precipitate. A 15 min incubation was carried at room temperature in a $3 \mathrm{~m}$ glycine buffer, $\mathrm{pH} 3.6$ in between the two immunodetections. This step was aimed at removing any residual immunoglobulin that may remain unbound to the biotinylated secondary antibody.

In situ hybridization. The antisense TGF $\alpha$ cRNA probe used was obtained by in vitro transcription of a 400 bp EcoRI/HindIII cDNA

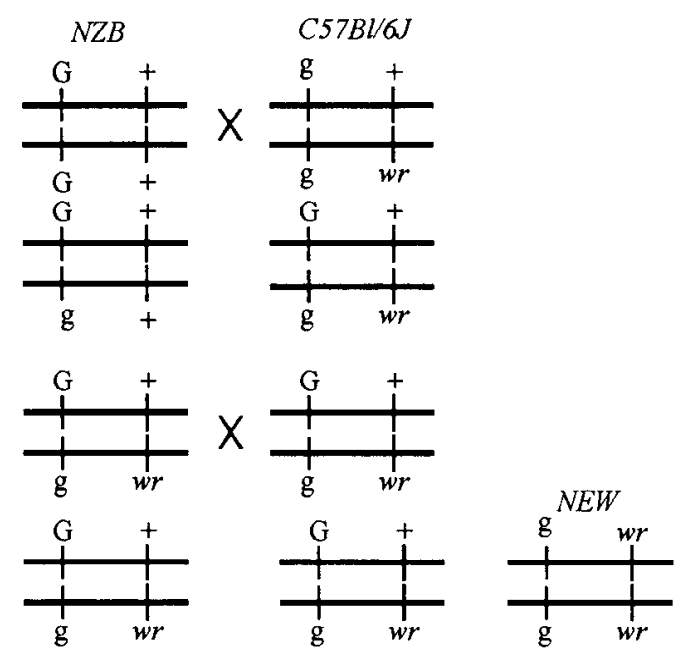

Figure 1. Scheme of the intraspecific backcross used to obtain the "new" hybrids.

fragment corresponding to the coding region of the rat TGF $\alpha$ cDNA, subcloned into the pGEM $3 Z$ vector (Junier et al., 1991). The transcription was carried out as previously described (Junier et al., 1991) with substitution of ${ }^{32} \mathrm{P}-\mathrm{CTP}$ by DIG-UTP. The template was linearized either with EcoRI to obtain a $400 \mathrm{nt}$ digoxigenin-labeled antisense RNA using SP6 RNA polymerase, or with HindIII to obtain a $400 \mathrm{nt}$ digoxigenin-labeled sense RNA using T7 RNA polymerase. The transcripts were then subjected to limited alkaline hydrolysis to obtain fragments of approximately $160 \mathrm{nt}$ length (Chesselet et al., 1987). Six-week-old wobblers were perfused as for immunocytochemistry, and $30-\mu \mathrm{m}$-thick sections were cut on a cryostat, placed in an ethylene glycol-based cryoprotective solution (sucrose, $30 \%$; ethylene glycol, $30 \%$; in $0.1 \mathrm{~m}$ phosphate buffer, $\mathrm{pH} 7.2$ ), and stored at $-20^{\circ} \mathrm{C}$ before further processing. Hybridization was carried out following the protocol of Esclapez et al. (1993) for free-floating sections with minor modifications; that is, hybridization temperature was $42^{\circ} \mathrm{C}$ and probe concentration was $1 \mu \mathrm{g} /$ $\mathrm{ml}$. Concentration of the probe was determined through ethidium bromide-stained agarose dot blot.

\section{Results}

\section{Genetic diagnosis}

An example of the electrophorized products of PCR amplification is shown in Figure 2. Homozygotes for the wobbler mutation were characterized by a single light band of $180 \mathrm{bp}$ characteristic of the $g$ allele of the glutamine synthetase gene Heterozygotes exhibited two bands of 180 and $210 \mathrm{bp}$, respectively, while the NZB mice homozygotes for the $G$ allele exhibited a single 210 bp band.

\section{Clinical characteristics of the wobbler mice of the "new" lineage}

Mice of the "new" lineage presented the same phenotypic characteristics as mice of the original wobbler strain. The first clinical signs appeared at 3-4 weeks of age, and were followed by a period of rapid deterioration up to the third to fourth month. Thereafter, the course of the disease seemed to stabilize until death occurred. Clinical abnormalities were exemplified by a reduced body weight visible by the fourth week of age, clasping of the forepaws when suspended by the tail, and unsteadiness. At later stages of the disease, the motility was retained only in the hindlimbs. Heterozygotes $(+/ w r)$ presented a normal phenotype and were therefore indifferently used as controls with 
Figure 2. Example of electrophoresis on $4 \%$ agarose gel of the PCR amplification products used for the genetic diagnosis of "new" hybrids. Note the single band of 180 bp characteristic of homozygotes for the wobbler mutation.

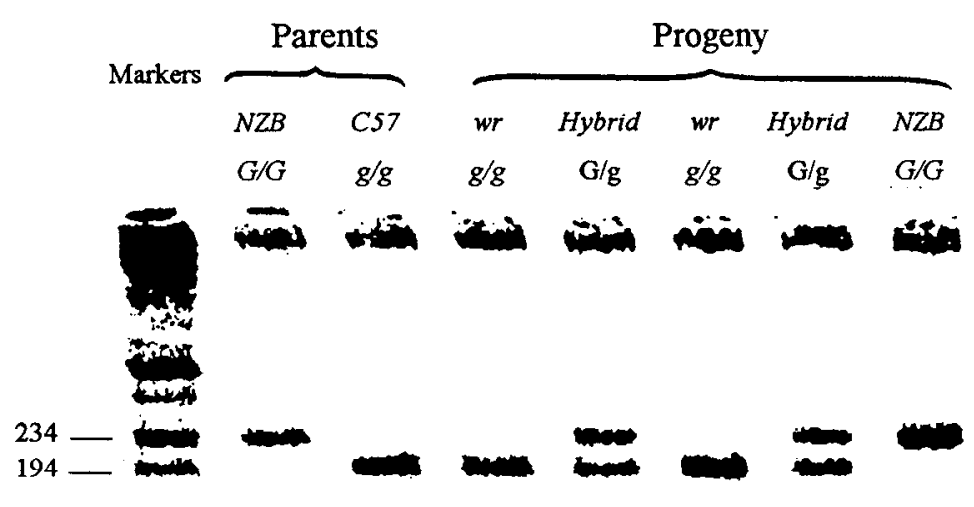

wild-type homozygotes $(+/+)$. Homozygotes for the wobbler mutation $(w r / w r)$ of the "new" lineage will be thereafter referred to as wobblers.

\section{General histological findings and development of astrogliosis}

Histological abnormalities, as observed in cresyl violet-stained sections, followed closely the development of the clinical symptoms, and were identical to the previous descriptions of the literature (Duchen and Strich, 1968; Andrews, 1975). Briefly, the typical characteristics of the wobbler motoneurons were first observed in 4-week-old mutants where normal motoneurons coexisted with nerve cells exhibiting various stages of degeneration. The affected motoneurons presented an enlarged soma, poorly stained Nissl bodies, a reduced number of dendrites, and, in the worst cases, a simple swollen soma filled with vacuoles (data not shown). As the disease developed, the number of degenerating neurons increased. In aged wobblers (5 months old) degenerative neuronal figures were rare and the number of healthy motoneurons was greatly reduced. No degenerating motoneurons were visible prior to the appearance of the clinical symptoms in 2-week-old wobblers.

Development of astrogliosis was defined as the presence within the gray matter of increased numbers of astrocytes intensely immunoreactive for GFAP. Up to 4 weeks of age, controls and wobblers exhibited the same pattern of GFAP immunoreactivity (Fig. $3 A-C$ ). At later ages, staining was essentially localized in control mice within the white matter, with some astrocytes in the gray matter (data not shown). In 4-week-old wobblers, the number of GFAP-immunoreactive astrocytes was increased in the ventral white matter as compared to age-matched controls (Fig. $3 C$ ). At 6 weeks of age, the pattern of GFAP staining was markedly altered in wobblers. Numerous GFAP-immunoreactive astrocytes were present in the white matter as well as within the gray matter of the spinal cord (Fig. 3D). At later stages of the disease, at 3 and 5 months of age, the pattern of GFAP staining was again similar to the age-matched controls, and essentially localized within the white matter (Fig. $3 E, F$ ).

Time course of pro-TGF $\alpha$ immunoreactivity in the wobbler cervical spinal cord

In both controls and wobbler, and at all ages studied, pro-TGF $\alpha-$ immunoreactive neurons were observed in the dorsal horn of the spinal cord as well as in a few small-sized neurons localized in the ventral horn. In addition, a few astrocytes were lightly stained in the white matter.

In 2-week-old wobblers and controls, immunoreactive large neurons were observed in the ventral horn (Fig. $4 A$ ). In older control mice, large neurons of the ventral horn were no longer stained (Fig. $4 B$ ). In contrast, in 4-week-old wobblers, large cells immunoreactive for pro-TGF $\alpha$ were observed in the ventral horn (Fig. 4C). Some of these cells displayed the typical morphological aspect of a motoneuron, with a large multipolar soma, although with swollen dendritic trunks (Fig. 4D). Most of the pro-TGF $\alpha$-immunoreactive motoneurons showed, however, signs of degeneration exemplified by a swollen soma with irregular contours or even a total lack of dendrites (Fig. $4 E, F$ ). The immunocytochemical staining was also variable, ranging from homogeneous staining of the entire neuron (Fig. $4 D$ ) to a dense staining around the nucleus (Fig. 4E,F). In 6-week-old wobblers, the number of pro-TGF $\alpha$-immunoreactive large neurons increased dramatically in the ventral horn (Fig. $5 A$ ). Pro$\mathrm{TGF} \alpha$ immunostaining was especially strong in the cell soma but extended to dendrites that formed a dense network in the ventrolateral part of the spinal cord (Fig. 5B). The immunoreactive neurons had large cell somas with irregular contours (Fig. $5 C, D$ ), and often a cytoplasm filled with vacuoles (Fig. $5 C$ ). Preadsorbtion of the antiserum with its antigen suppressed both astrocytic and motoneuronal pro-TGF $\alpha$ staining in 6-weekold wobblers (Fig. 6C,D). Identification of the pro-TGF $\alpha$-immunoreactive neurons as cells synthesizing effectively pro- $\mathrm{IGF} \alpha$ was further achieved by in situ hybridization. In 6-week-old wobblers numerous large neurons presented a strong signal with the antisense TGF $\alpha$ RNA probe (Fig. 6B). Labeling was confined to the cytoplasm of the cell bodies and the nucleus was free of reaction product. Specificity of the labeling was verified by hybridization of adjacent sections with the sense TGF $\alpha$ probe. In this case, no labeling was observed (Fig. 6A). In 3-month-old wobblers, the number of pro-TGF $\alpha$-immunoreactive neurons had regressed (Fig. 5F). The large majority of the labeled motoneurons exhibited strong degenerative signs, and were localized in the ventral most part of the ventral horn. In 5-monthold wobblers, an age when motoneuron degeneration has reached its apex, rare pro-TGF $\alpha$-immunoreactive motoneurons were present (Fig. $5 G$ ). Most were rounded cells with a swollen soma devoid of any dendritic extension.

Parallel to the development of pro-TGF $\alpha$ immunoreactivity in motoneurons, an apparent increase in the number of proTGF $\alpha$-immunoreactive astrocytes was observed, starting from 4 weeks of age (Fig. $4 C$ ). The identity of these pro-TGF $\alpha-$ immunoreactive cells as astrocytes was achieved with double immunocytochemical labeling (data not shown). While in controls, pro-TGF $\alpha$-immunoreactive astrocytes were especially localized along the ventral nerve roots (Fig. $4 B$ ), in wobblers they were observed throughout the whole ventral white matter (Fig. 

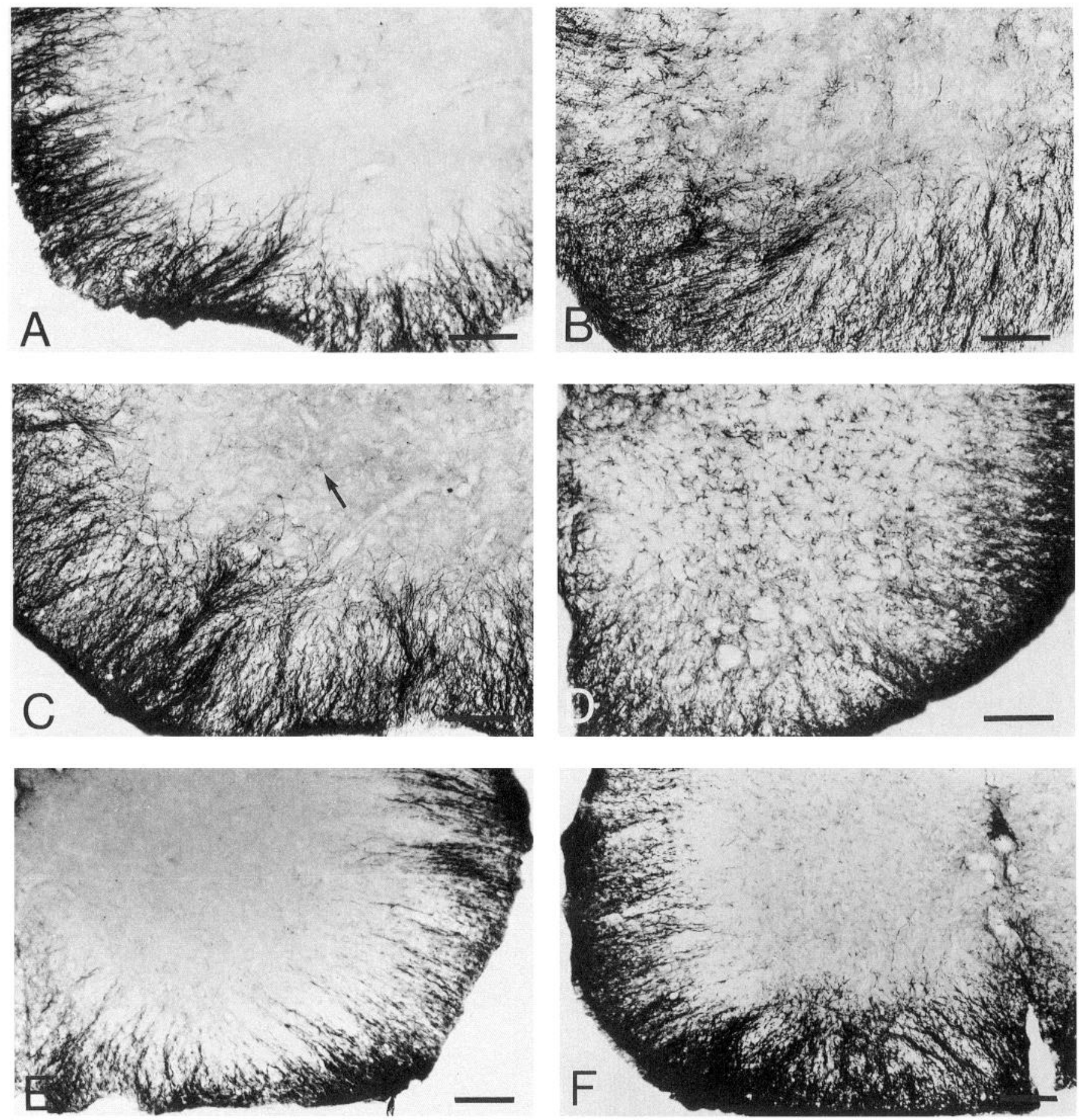

Figure 3. Astrogliosis development in the ventral horn of the cervical spinal cord over the course of the wobbler disease as revealed with GFAP immunostaining. $A$, Two-week-old control. $B$, Four-week-old control. Note the staining essentially localized in the white matter, and the rare labeled astrocytes within the gray matter. Except in 2-week-old mice, which exhibited a more intense GFAP immunoreactivity, controls of all ages presented a similar staining pattern. $C$, Four-week-old wobbler. Note the increase in the number and the intensity of labeling of the GFAPimmunoreactive astrocytes in the white matter as compared to the age-matched control, and the paucity of labeled astrocytes within the gray matter (arrow). D, Six-week-old wobbler. Numerous astrocytes, intensely immunoreactive for GFAP, are apparent throughout the gray matter. $E$, Threemonth-old wobbler. F, Five-month-old wobbler. In aged wobblers, intensely GFAP-immunoreactive astrocytes are localized in the white matter. Scale bars, $100 \mu \mathrm{m}$.

$4 C)$. In addition, the pro-TGF $\alpha$-immunoreactive astrocytes appeared thicker, with greater processes in wobblers than in controls. In 6-week-old wobblers, numerous pro-TGF $\alpha$-immunoreactive astrocytes could be observed throughout the gray matter
(Fig. 5E). In older wobblers, this staining pattern disappeared and pro-TGF $\alpha$-immunoreactive astrocytes were, as in 2- and 4-week-old wobblers, localized within the white matter (Fig. $5 F, G)$. 

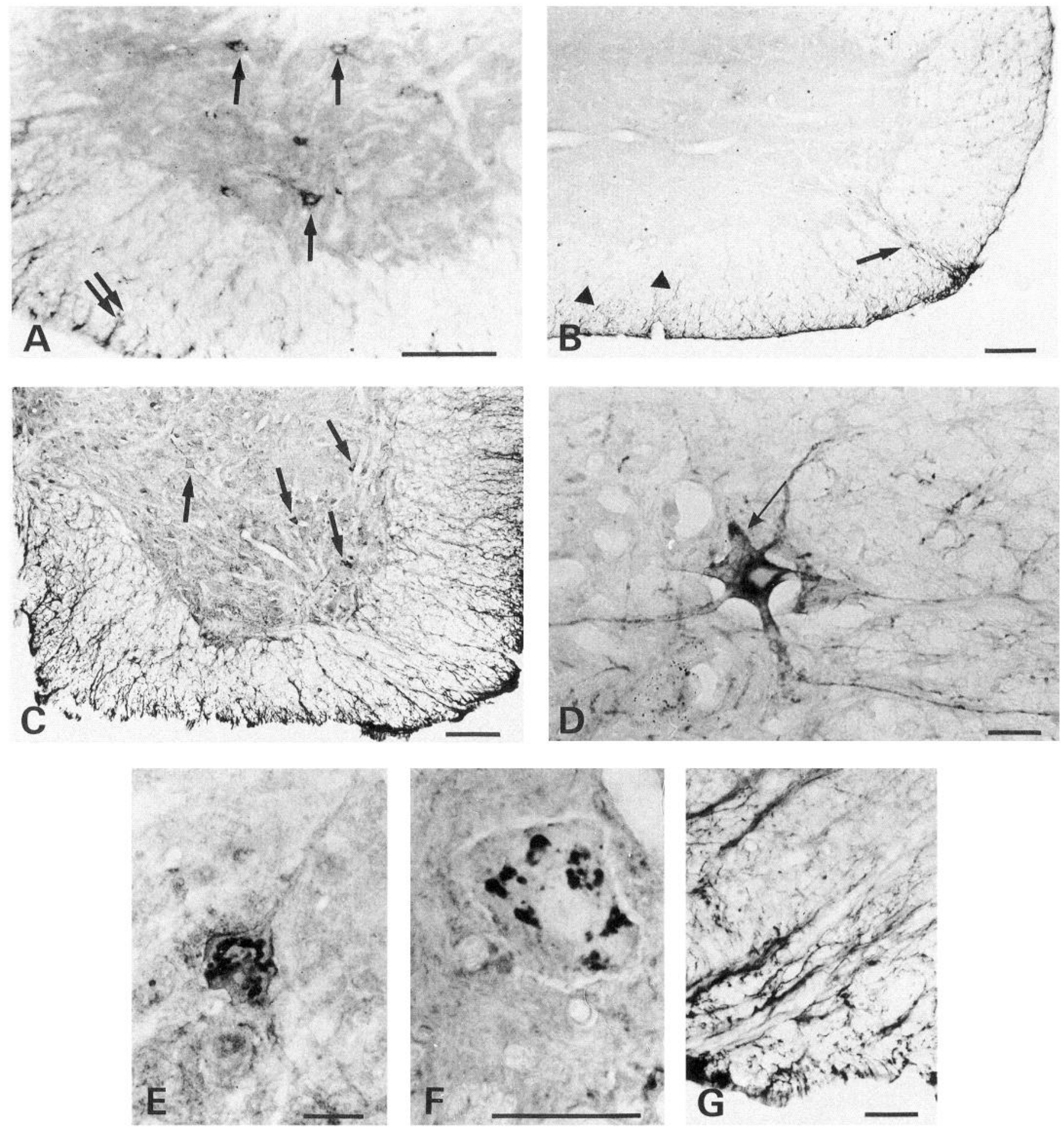

Figure 4. Pro-TGF $\alpha$ immunoreactivity in the ventral horn of the cervical spinal cord over the first postnatal month. $A$, Two-week-old control. Note the presence of pro-TGF $\alpha$-immunoreactive neurons within the gray matter (arrows) and the rare labeled astrocytes localized at the external border of the white matter (double arrows). The staining was identical in age-matched wobblers. B, Four-week-old control. Note the absence of labeled cells in the gray matter and the pro-TGF $\alpha$-immunoreactive astrocytes in the white matter (arrowheads), more apparent along the ventral nerve root (arrow). Pro-TGF $\alpha$ staining was identical in older control mice. $C$, Four-week-old wobbler. Pro-TGF $\alpha$-immunoreactive cells are visible within the gray matter (arrows), and numerous labeled astrocytes are present throughout the white matter. $D-F$, Examples of pro-TGF $\alpha$-immunoreactive motoneurons in 4-week-old wobbler. Some presented the typical aspect of a motoneuron with multipolar soma $(D)$, although the dendritic trunks appeared enlarged (arrow). Others showed strong signs of degeneration $(E, F)$ with a swollen and irregular soma. Note the punctate staining localized around the nucleus in both cases. $G$. High-power view of pro-TGF $\alpha$-immunoreactive astrocytes in the white matter of 4-week-old wobbler. Scale bars: $A-C, 100 \mu \mathrm{m} ; D-G, 25 \mu \mathrm{m}$. 

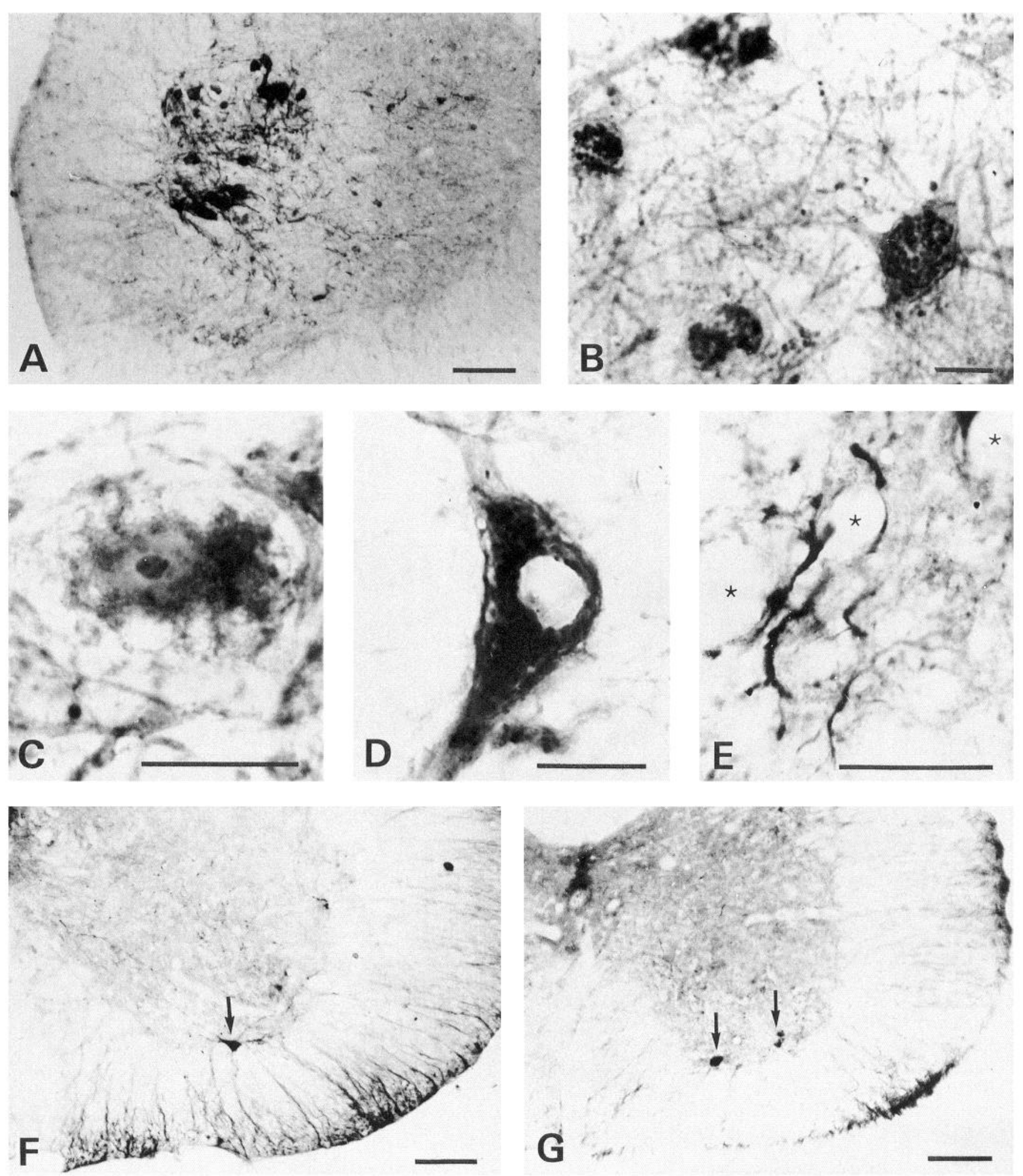

Figure 5. Pro-TGF $\alpha$ immunoreactivity in the ventral horn of the cervical spinal cord in 6-week-old, 3- and 5-month-old wobblers. A, Six-weekold wobbler. Numerous pro-TGF $\alpha$-immunoreactive motoneurons are visible in the ventral horn. B, Six-week-old wobbler. Labeled dendrites form a dense network. Note the intense punctate staining in the soma. $C$ and $D$, Example of pro-TGF $\alpha$-immunoreactive motoneurons in 6 -week-old wobbler. Note the enlarged soma and, in $C$, the vacuoles filling the cytoplasm. In $C$, the nucleolus appears labeled as a result of cresyl violet counterstaining. $E$, High-power view of pro-TGF $\alpha$-immunoreactive astrocytes within the gray matter of 6-week-old wobbler. Asterisks mark blood vessels. $F$, Three-month-old wobbler. $G$, Five-month-old wobbler. Note in both cases the rare pro-TGF $\alpha$-immunoreactive motoneurons (arrows). Scale bars: $A, F$, and $G, 100 \mu \mathrm{m} ; C-E, 25 \mu \mathrm{m}$. 

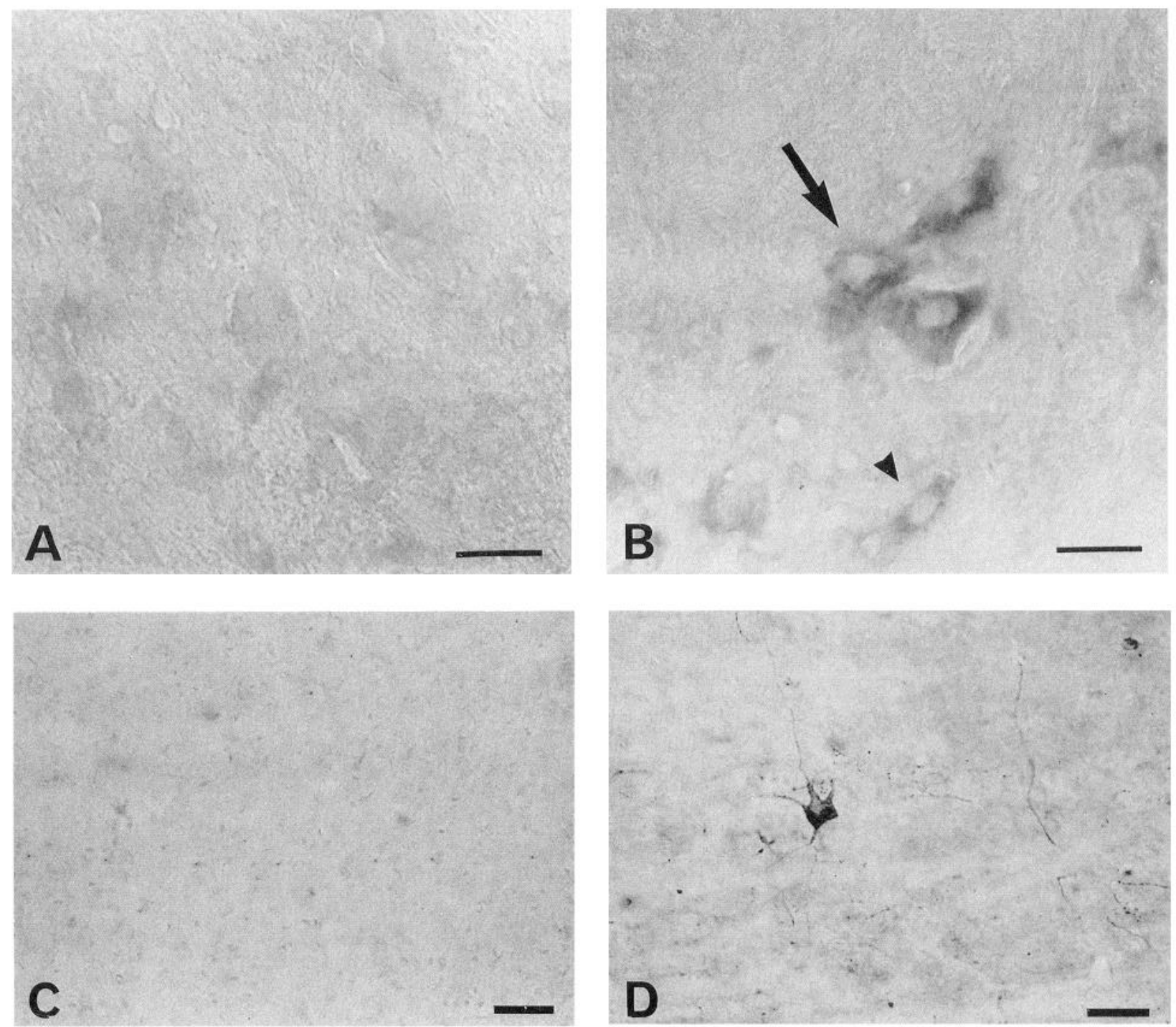

Figure 6. Detection of TGF $\alpha$ mRNA in motoneurons of the ventral horn of the cervical spinal cord in 6-week-old wobbler. $A$, Sense-TGF $\alpha$ digoxigenin-labeled riboprobe. Note the absence of staining. $B$, Example of motoneurons detected with the antisense TGF $\alpha$ digoxigenin-labeled riboprobe (arrow). In addition to motoneurons, labeled cells of small size were observed (arrowhead). $C$, Pro-TGF $\alpha$ antiserum preabsorbed with its antigen. Note the absence of staining as compared with the section incubated with the pro-TGF $\alpha$ antiserum alone and depicted in $D$. In $C$ and $D$, sections were lightly counterstained with cresyl violet. Six-week-old wobbler, horizontal sections. Scale bars: $A$ and $B, 25 \mu \mathrm{m} ; C$ and $D, 50 \mu \mathrm{m}$.

\section{Time course of TGF $/$ EGF receptor immunoreactivity}

Putative targets of TGF $\alpha$ were immunostained with an antibody raised against the intracellular portion of the $\mathrm{TGF} \alpha / \mathrm{EGF}$ receptor. At all ages, and in both controls and mutant mice, TGF $\alpha /$ EGF receptor immunoreactivity was exclusively localized in astrocytes (Fig. 7). Identification of the TGF $\alpha /$ EGF receptorimmunoreactive cells as astrocytes was confirmed by double immunocytochemistry (data not shown). In controls of all ages,
TGF $\alpha /$ EGF receptor immunoreactivity was restricted to a few astrocytes localized at the external border of the white matter (Fig. $7 A, B$ ). In 2-week-old wobblers, staining was identical to age-matched controls (Fig. 7C). In 4-week-old wobblers this staining pattern extended to astrocytes developing their processes throughout the entire white matter (Fig. 7D), and in 6-week-old wobblers, TGF $\alpha / \mathrm{EGF}$ receptor-immunoreactive astrocytes were also present within the ventral part of the gray matter (Fig. $7 E, F$ ). In older wobblers, TGF $\alpha /$ EGF receptor-

Figure 7. Time course of TGF $\alpha /$ EGF receptor immunoreactivity in the ventral cervical spinal cord of wobbler and control mice. $A$, Two-weekold control, cresyl violet counterstaining. $B$, Four-week-old control. In controls of all ages, the staining was restricted to rare astrocytes localized at the external border of the white matter (arrows). Cresyl violet counterstaining. $C$, Two-week-old wobbler. Note the identity of the staining with 2 -week-old control. Arrow points to labeled astrocyte in the white matter. $D$, Four-week-old wobbler. Labeled astrocytes with developed processes are visible throughout the white matter (arrowheads). E. Six-week-old wobbler. In addition to the white matter (arrow), labeled astrocytes are observed within the gray matter (arrowheads). $F$. High-power view of TGF $\alpha$ /EGF receptor-immunoreactive astrocytes (arrow) within the ventral gray matter of 6-week-old wobbler. G, Five-month-old wobbler. Localization of TGF $\alpha /$ EGF receptor immunoreactive astrocytes (arrowheads) was restricted to the white matter. Scale bars: $A-D, F$, and $G, 25 \mu \mathrm{m} ; E, 100 \mu \mathrm{m}$. 


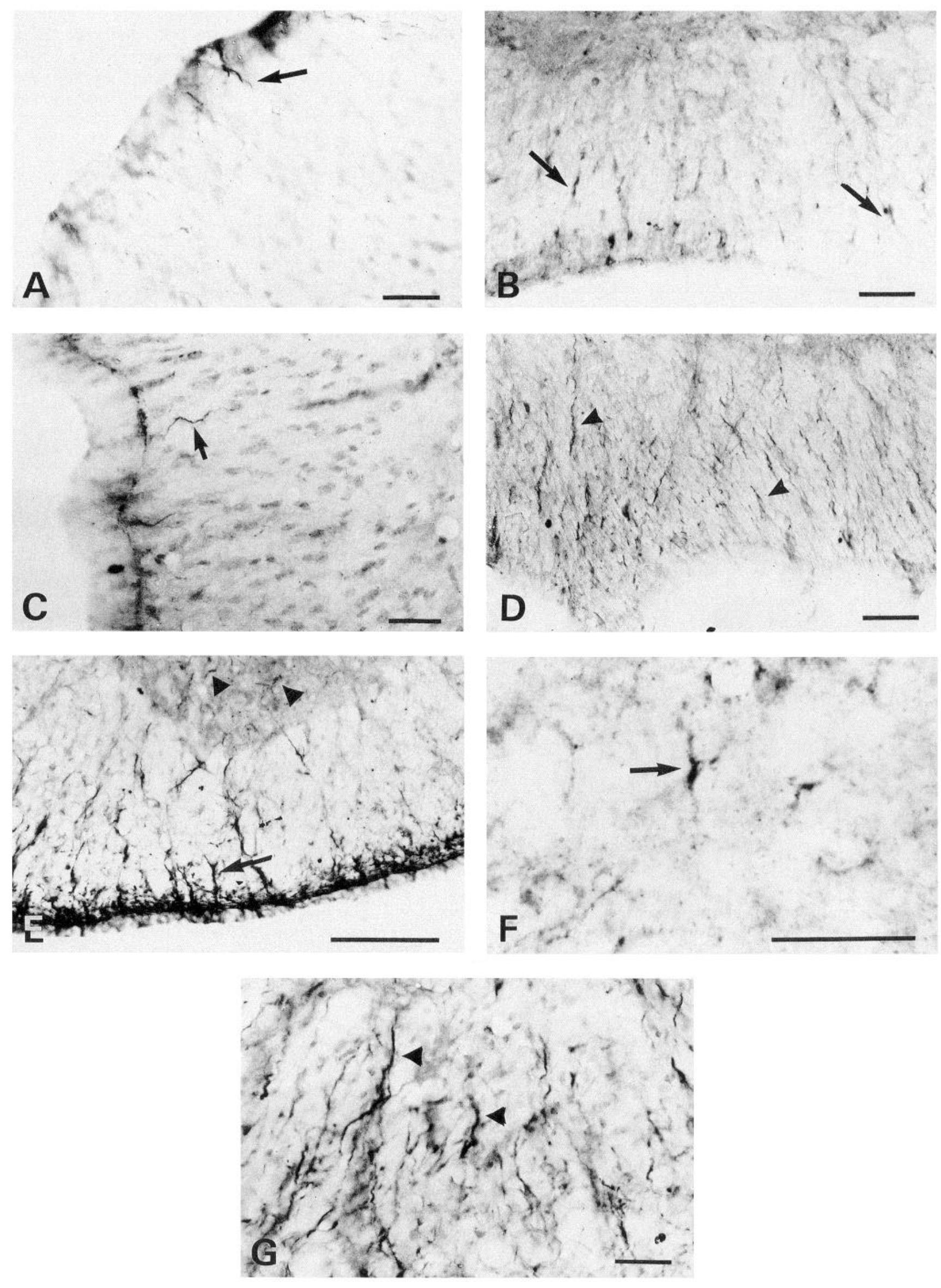


immunoreactive astrocytes disappeared from the gray matter, and were confined to the white matter (Fig. $7 G$ ).

\section{Discussion}

The availability of a genetic diagnosis of the wobbler phenotype allowed us to perform a precise time course investigation of the coordinated development of motoneuronal degeneration and astrogliosis. Such a study has not previously been possible, as identification of homozygotes for the mutation relied upon the appearance of clinical symptoms.

To date, we obtained in the progeny of the intraspecific backcross, 107 wobbler mice carrying both the C57 Bl/6J allele of the glns gene $(\mathrm{g})$, and the wobbler mutation. None of these mice was a recombinant, an observation consistent with the close genetic linkage existing between the $w r$ and the glns genes (Des Portes et al., 1993). Thus, young mice that exhibited the light band corresponding to the $\mathrm{g}$ allele were considered as wobbler before the onset of the disease.

The histological signs of degeneration were similar to those reported in the original wobbler strain and became worse as the disease developed (Duchen et al., 1966; Duchen and Strich, 1968; Andrews, 1975; Ma and Vacca-Galloway, 1991). Thus, the intraspecific backcross used to obtain genetically diagnosed mice of the "new" lineage did not alter the expression of the wobbler phenotype. The absence of degenerative figures in young wobblers, prior to the appearance of the clinical symptoms, suggests that the onset of motoneuronal degeneration is a relatively late occurring event in the wobbler disease. However, a final definition of the time of onset of the motoneuronal disease awaits further studies at the ultrastructural level.

Astrogliosis has been reported as the other major cellular alteration of 2-month-old wobblers (Laage et al., 1988). Our results show that astrogliosis is an event that follows the onset of neurodegeneration, suggesting that motoneurons are the cell population the most precociously affected by the disease. Thus, in wobblers, astrogliosis does not appear to differ in its initial developmental stages from the general astrocytic reactivity induced by the various alterations of nervous tissues, in the sense that it appears subsequent to neuronal alteration and does not precede it (Nathaniel and Nathaniel, 1981; Reier, 1986). However, in contrast to the usually reported permanence over time of astrogliosis at the site of neuronal loss (Reier, 1986), the present data show that astrogliosis is a transitory phenomenon in wobblers, regressing as the number of degenerating motoneurons decreases. Reversal of astrocytic activation appears to be a rare event, at least in experimental models. To our knowledge, it has been reported in only three other systems: the rat olfactory bulb following axotomy (Anders and Johnson, 1990), the facial nucleus after nerve crush (Streit and Kreutzberg, 1988), and the chick cochlear nucleus following pharmacological blockade of different activity (Canady and Rubel, 1992). If in these three systems the reversal of astrocytic activation may be attributed to the restoration of normal function due either to the regenerative capabilities of the olfactory neurons and of the crushed facial nerve or to the restoration of normal afferent activity, the functional significance of the transitory nature of astrogliosis in wobbler remains elusive. The astroglial reaction has been thought to be ultimately aimed at filling the empty space left by the dying neurons (Björklund et al., 1986; Reier, 1986). In the old wobbler, the loss of neurons is not compensated by an increased number of glial cells but simply by an overall reduction in the spinal cord size (Andrews, 1975). The transitory nature of astrogliosis observed in wobblers could be a common feature of noninvasive neurodegenerative events, an eventuality that requires exploration of other models of spontaneously occurring neurodegeneration. Alternatively, it may reflect complex events related to the nature of the interactions between the affected motoneurons and the reactive astrocytes specific to the wobbler mutant.

\section{Pro-TGF $\alpha$ in the wobbler motoneurons}

Mature TGF $\alpha$ derives from the proteolytic cleavage of its transmembrane precursor (Derynck, 1988). The use of an antiserum that recognizes the intracellular portion of the TGF $\alpha$ precursor ensured the identification of the cells that synthesize TGF $\alpha$, as opposed to cells capable of binding the growth factor. In situ hybridization studies and preadsorbtion of the antiserum with its antigene confirmed that pro-TGF $\alpha$-immunoreactive cells corresponded to neurons synthesizing true pro-TGF $\alpha$.

Motoneuronal pro-TGF $x$ production appeared closely linked to the degenerative status of the motoneurons and to the course of the wobbler illness. All pro-TCFF $\alpha$-immunoreactive motoneurons presented signs of degeneration. These signs ranged from a simple swelling of the dendritic trunks to modification of the whole motoneuronal structure, including swelling of the cell body and disappearance of the dendrites.

Pro-TGF $\alpha$ is synthesized by motoneurons over the first two postnatal weeks in control mice, while adult motoneurons are devoid of pro-TGF $\alpha$. The reappearance of pro-TGF $\alpha$ synthesis in affected motoneurons and adolescent and adult wobbler suggests that they undergo a dedifferentiation process triggered by the disease and, therefore, that production of TGF $\alpha$ reflects a stereotypic reactivation of a developmental program. This hypothesis is supported by the observation of a decreased expression of two of the main molecular phenotypic markers of motoneurons, acetylcholine esterase and calcitonin gene-rclatcd peptide (Vacca-Galloway and Steinberger, 1986; Zhang and Vacca-Galloway, 1992), reminiscent of the motoneuronal phenotype over its developmental period (Marti et al., 1987).

\section{Pro-TGF $\alpha$ and $T G F \alpha / E G F$ receptor in wobbler astrocytes}

Enhanced pro-TGF $\alpha$ and TGF $\alpha / E G F$ receptor expression in reactive astrocytes has been observed in vivo in various brain structures following acute injury (Nieto-Sampedro et al., 1988 Junier et al., 1991, 1993). Our observation of pro-TGF $\alpha$ and TGF $\alpha /$ EGF receptor production by reactive astrocytes developing in a neurodegenerative process of genetic origin extends these previous results to situations in which neurons affected by the degenerative process, but not yet eliminated, coexist with reactive astrocytes. Thus, these results further suggest that enhanced TGF $\alpha$-TGF $\alpha / \mathrm{EGF}$ receptor synthesis is a general property of reactive astrocytes, regardless of the nature of the injury or of its anatomical localization.

The initial signal triggering astrocytic reactivity remains unknown. Factors derived from the blood elements and/or activated microglia have been implicated in the induction of astrogliosis on the basis of in vitro studies and models of severe neuronal trauma (Nieto-Sampedro and Cotman, 1985; Streit and Kreutzberg, 1988). Although such mechanisms remain possible in the wobbler spinal cord, our results suggest another possibility. The production of pro-TGF $\alpha$ by the motoneurons prior to astroglial activation, and the close parallel between the increased number of pro-TGF $\alpha$-immunoreactive motoneurons and the development of astrogliosis suggest a neuronal origin in the induction of astrogliosis. In vitro, EGF, the functional 
homolog of TGF $\alpha$, has been shown to exert on astrocytes both mitogenic (Leutz and Schachner, 1981; Simpson et al., 1982) and differentiative effects such as enhanced synthesis of cytoskeletal proteins (Bockus and Stiles, 1984), production of extracellular soluble proteins (Wang et al., 1989), and increased enzymatic activities (Honegger and Guentert-Lauber, 1983), all effects mediated by activation of the TGF $\alpha / E G F$ receptor (Wang et al., 1989). In light of these results, and of the present work, we propose that, in the wobbler mouse, TGF $\alpha$ synthesized by the motoneurons acts on the astrocytes to stimulate their differentiation, through, notably, enhanced GFAP, TGF $\alpha$, and TGF $\alpha$ /EGF receptor synthesis. Synthesis of TGF $\alpha$ and TGF $\alpha$ / EGF receptor by the astrocytes could play the role of amplifying the initial signal received from the motoneurons, a hypothesis supported by the reported stimulatory action of TGF $\alpha$ on the transduction of its own gene in cultured astrocytes (Ma et al., 1992) and other cell systems (Coffey et al., 1987).

\section{$T G F \alpha, T G F \alpha / E G F$ receptor and the wr mutation}

The mutation at the origin of the wobbler disease has been genetically mapped to chromosome 11 , at 2 centimorgans of the c-erB B proto-oncogene, which encodes the TGF $\alpha / E G F$ receptor (Kaupmann et al., 1992). Although the TGF $\alpha$ gene itself has been assigned to the murine chromosome 6 (Fowler et al., 1993), it is tempting to speculate that the striking correlation between the increased production of TGF $\alpha$ and the degeneration of motoneurons reflects a link between the $w r$ gene mutant itself and the TGF $\alpha$-TGF $\alpha /$ FGF receptor metabolic system. This speculation finds another basis in the involvement of the TGF $\alpha$ $\mathrm{TGF} \alpha / \mathrm{EGF}$ receptor couple in the two other systems that are deficient in the wobbler mutation, that is, spermatogenesis and growth. Indeed, TGF $\alpha$ has been implicated in the developmental control of the seminiferous tubules (Mullaney and Skinner, 1992), and TGF $\alpha, E G F$, and their common receptor participate in numerous mechanisms controlling growth development (Brown et al., 1990; Jhappan et al., 1990; Sandgren et al., 1990). The possibility that the $w r$ gene encodes a transcription factor capable of acting on the transcription rate of the TGF $\alpha$ and/or the erB B genes deserves further attention.

\section{References}

Anders JJ, Johnson JA (1990) Transection of the rat olfactory nerve increases glial fibrillary acidic protein immunoreactivity from the olfactory bulb to the piriform cortex. Glia 3:17-25.

Andrews JM (1975) The fine structure of the cervical spinal cord, ventral root and brachial nerves in the wobbler (wr) mouse. J Neuropathol Exp Neurol 34:12-27.

Baulac M, Rieger F, Meininger V (1983) The loss of motoneurons corresponding to specific muscles in the wobbler mutant mouse. Neurosci Lett 37:99-104.

Björklund H, Olson L, Dahl D, Scwarcz R (1986) Short and longterm consequences of intracranial injections of the excitotoxin, quinolinic acid, as evidenced by GFAP immunohistochemistry of astrocytes. Brain Res 371:267-277.

Bockus BJ, Stiles CD (1984) Regulation of cytoskeletal architecture by platelet-derived growth factor, insulin and epidermal growth factor. Exp Cell Res 153:186-197.

Brown PI, Lam R, Iakshmanan, Fisher DA (1990) Transforming growth factor alpha in developing rats. Am J Physiol 259:E256-E260.

Canady KS, Rubel EW (1992) Rapid and reversible astrocytic reaction to afferent activity blockade in chick cochlear nucleus. J Neurosci 12: 1001-1009.

Chalazonitis A, Kessler JA, Twardzik DR, Morrison RS (1992) Transforming growth factor $\alpha$, but not epidermal growth factor, promotes the survival of sensory neurons in vitro. J Neurosci 12:583-594.

Chesselet MF, Weiss L, Wuenschell C, Tobin AJ, Affolter HU (1987)
Comparative distribution of mRNAs for glutamic acid decarboxylase, tyrosine hydroxylase, and tachykinins in the basal ganglia: an in situ hybridization study in the rodent brain. J Comp Neurol 262:125140.

Coffey RJ Jr, Derynck R, Wilcox JN, Bringman TS, Goustin AS, Moses HL, Pittelkow MR (1987) Production and auto-induction of transforming growth factor-alpha in human keratinocytes. Nature 328: $817-820$.

Derynck R (1988) Transforming growth factor $\alpha$. Cell 54:593-595.

DesPortes V, Coulpier M, Melki J, Guénet JL, Dreyfus PA (1994) Close genetic linkage between the glutamine synthetase locus and wobbler mutation in the mouse. Mammal Genome, in prcss.

Duchen LW, Strich SJ (1968) An hereditary motor neurone disease with progressive denervation of muscle in the mouse: the mutant "wobbler." J Neurol Neurosurg Psychiatry 31:535-542.

Duchen LW, Falconer DS, Strich SJ (1966) Hereditary progressive neurogenic muscular atrophy in the mouse. J Physiol (Lond) 183:5355 .

Eddleston M, Mucke L (1993) Molecular profile of reactive astrocytesimplications for their role in neurologic disease. Neuroscience 54:1536.

Esclapez M, Tillakaratne NJK, Tobin AJ, Houser CR (1993) Comparative localization of mRNAs encoding two forms of glutamic acid decarboxylase with nonradioactive in situ hybridization methods. J Comp Neurol 331:339-362.

Fallon JH, Annis CM, Gentry LE, Twardzik DR, Loughlin SE (1990) Localization of cells containing transforming growth factor- $\alpha$ precursor immunoreactivity in the basal ganglia of the adult rat brain. Growth Factors 2:241-250.

Fowler KJ, Mann GB, Dunn AR (1993) Linkage of the murine transforming growth factor-alpha gene with Igk, Ly-2, and Fabpl on chromosome-6. Genomics 16:782-784.

Gentry LE, Twardzik DR, Lim GJ, Ranchalis JE, Lee DC (1987) Expression and characterization of transforming growth factor alpha precursor protein in transfected mammalian cells. Mol Cell Biol 7:1585-1591.

Honegger P, Guentert-Lauber B (1983) Epidermal growth factor(EGF) stimulation of cultured brain cells. I. Enhancement of the developmental increase in glial enzymatic activity. Dev Brain Res 11:245251.

Jhappan C, Stahle C, Harkins RN, Fausto N, Smith GH, Merlino GT (1990) TGF $\alpha$ overexpression in transgenic mice induces liver neoplasia and abnormal development of the mammary gland and pancreas. Cell 61:1137-1146.

Junier MP, Peschanski M (1992) Induction of neurotrophic factors genes expression in the kainic acid lesioned thalamus. Soc Neurosci Abstr 18.

Junier MP, Ma YI, Costa MA, Hoffman G, Hill DF, Ojeda SR (1991) Transforming growth factor $\alpha$ contributes to the mechanism by which hypothalamic injury induces precocious puberty. Proc Natl Acad Sci USA 88:9743-9747.

Junier MP, Hill DF, Costa ME, Felder SE, Ojeda SR (1993) Hypothalamic lesions that induce female precocious puberty activate glial expression of the epidermal growth factor receptor gene: differential regulation of alternatively spliced transcripts. J Neurosci 13:703-713

Kaupmann K, Simon-Chazottes D, Guénet JL, Jockusch H (1992) Wobbler, a mutation affecting motoneuron survival and gonadal functions in the mouse, maps to proximal chromosome 11. Genomics 13:39-43.

Kudlow JE, Leung AWC, Kobrin MS, Paterson AJ, Asa SL (1989) Transforming growth factor $-\alpha$ in the mammalian brain. J Biol Chem $264: 3880-3883$

Laage S, Zobel G, Jockusch H (1988) Astrocyte overgrowth in the brain stem and spinal cord of mice affected by spinal atrophy, wobbler. Dev Neurosci 10:190-198.

Leutz A, Schachner M (1981) Epidermal growth factor stimulates DNA-synthesis of astrocytes in primary cerebellar cultures. Cell Tissue Res 220:393-404.

Ma W, Vacca-Galloway LL (1991) Reduced branching and length of dendrites in cervical spinal cord motoneurons of wobbler mouse, a model for inherited motoneuron disease. J Comp Neurol 31:210222.

Ma YJ, Hill DH, Costa ME, Ojeda SR (1992) Regulation of transforming growth factor alpha mRNA expression in rat hypothalamic astrocytes by TGF $\alpha$ and estradiol. Soc Neurosci Abstr 18. 
Marti E, Gibson SJ, Polak JM, Facer P, Springall DR, Van Aswegen G, Aitchison M, Koltzenburg M (1987) Ontogeny of peptide- and amine-containing neurones in motor, sensory, and autonomic regions of rat and human spinal cord, dorsal root ganglia, and rat skin. J Comp Neurol 266:332-359.

Mullaney BP, Skinner MK (1992) Transforming growth factor- $\alpha$ and epidermal growth factor receptor gene expression and action during pubertal development of the seminiferous tubule. Mol Endocrinol 6:2103-2113.

Nathaniel EJH, Nathaniel DR (1981) The reactive astrocyte. Adv Cell Neurobiol 2:249-301.

Nieto-Sampedro M, Cotman CW (1985) Growth factor induction and temporal order in central nervous system repair. In: Synaptic plasticity (Cotman CW, ed), pp 407-455. New York: Guilford.

Nieto-Sampedro M, Gomez-Pinilla F, Knauer DJ, Broderick JT (1988) Epidermal growth factor receptor immunoreactivity in rat brain astrocytes. Response to injury. Neurosci Lett 91:276-282.

Reier PJ (1986) Gliosis following CNS injury: the anatomy of astrocytic scars and their influences on axonal elongation. In: Astrocytes (Federoff and Vernadakis, eds), pp 263-324. New York: Academic.

Sandgren EP, Luetteke NC, Palmiter RD, Brinster RL, Lee DC (1990) Overexpression of TGF $\alpha$ in transgenic mice: induction of epithelial hyperplasia, pancreatic carcinoma, and carcinoma of the breast. Cell 61:1121-1135
Seroogy KB, Lundgren KH, Lee DC, Guthrie KM, Gall GM (1993) Cellular localization of transforming growth factor- $\alpha$ mRNA in rat forebrain. J Neurochem 60:1777-1782.

Simpson DL, Morrison R, de Vellis J, Herschman HR (1982) Epidermal growth factor binding and mitogenic activity on purified populations of cells from the central nervous system. J Neurosci Res $8: 453-462$.

Streit WJ, Kreutzberg GW (1988) Response of endogenous glial cells to motor neurnn degeneration induced by toxic ricin. J Comp Neurol 268:248-263.

Vacca-Galloway LL, Steinberger CC (1986) Substance P neurons sprout in the cervical spinal cord of the wobbler mouse: a model for motoneuron disease. J Neurosci Res 16:657-670.

Wang SL, Shiverick KT, Ogilvie S, Dunn WA, Raizada MK (1989) Characterization of epidermal growth factor receptor in astrocytic glial and neuronal cells in primary culture. Endocrinology 124:240-247.

Wilcox JN, Derynck R (1988) Localization of cells synthesizing transforming growth factor-alpha mRNA in the mouse brain. J Neurosci $8: 1901-1904$.

Zhang YQ, Vacca-Galloway LL (1992) Decreased immunoreactive (IR) calcitonin gene-related peptide correlates with sprouting of IRpeptidergic and serotonergic neuronal processes in spinal cord and brain nuclei from the wohhler mouse during motoneuron diseasseBrain Res 587:169-177. 